\title{
Rationally Designed Complex, Hierarchical Microarchitectures
}

\section{Citation}

Noorduin, W. L., A. Grinthal, L. Mahadevan, and J. Aizenberg. 2013. “Rationally Designed

Complex, Hierarchical Microarchitectures.” Science 340 (6134) (May 16): 832-837. doi:10.1126/ science.1234621.

\section{Published Version}

doi:10.1126/science. 1234621

\section{Permanent link}

http://nrs.harvard.edu/urn-3:HUL.InstRepos:37255430

\section{Terms of Use}

This article was downloaded from Harvard University's DASH repository, and is made available under the terms and conditions applicable to Open Access Policy Articles, as set forth at http:// nrs.harvard.edu/urn-3:HUL.InstRepos:dash.current.terms-of-use\#OAP

\section{Share Your Story}

The Harvard community has made this article openly available.

Please share how this access benefits you. Submit a story.

Accessibility 


\title{
Rationally designed complex, hierarchical micro-architectures
}

\author{
Wim L. Noorduina*, Alison Grinthala , L. Mahadevana,a,c, Joanna Aizenberga,b,c,d* \\ ${ }^{a}$ School of Engineering and Applied Sciences, Harvard University, Cambridge, MA 02138; ${ }^{b}$ Wyss \\ Institute for Biologically Inspired Engineering, Harvard University, Boston, MA 02115; 'Kavli \\ Institute for Bionano Science and Technology, Harvard University, Cambridge, MA 02138; \\ ${ }^{\mathrm{d}}$ Department of Chemistry and Chemical Biology, Harvard University, Cambridge, MA 02138 \\ *Correspondence to: wnoord@seas.harvard.edu, jaiz@seas.harvard.edu
}

Single sentence summary: We rationally create arbitrarily sculpted complex hierarchical carbonate/silica microstructures in a reaction-diffusion system.

The emergence of complex nano/microstructures is of fundamental interest, and the ability to program their form has practical ramifications in fields such as optics, catalysis and electronics. We developed carbonate/silica microstructures in a dynamic reaction-diffusion system that allows us to rationally devise schemes for precisely sculpting a great variety of elementary shapes by diffusion of $\mathrm{CO}_{2}$ in a solution of barium chloride and sodium metasilicate. We identify two distinct growth modes and show how continuous and discrete modulations in $\mathrm{CO}_{2}$ concentration, $\mathrm{pH}$ and temperature can be used to deterministically switch between different regimes and create a bouquet of hierarchically assembled multiscale microstructures with unprecedented levels of complexity and precision. These results outline a nanotechnology strategy for "collaborating" with self-assembly processes in real time to build arbitrary tectonic architectures.

Natural patterns and shapes arise in innumerable ways on a range of scales and have fascinated artists and scientists alike $(1,2)$. Hierarchical nano/microarchitectures not only offer insight into how complex forms can emerge from simple starting materials, but also underlie coloration (3), wetting (4), mechanics (5), and other phenomena seen in nature and may transform optics (6), catalysis (7-9), building construction, and many other technologies if we can find ways to create them synthetically. Using top-down lithography techniques $(10,11)$, we can directly write and sculpt $3 \mathrm{D}$ patterns into a variety of materials, but at small scales this hands-on control translates into a laborious, costly, and often insufficient approach. Bottom-up self-assembly can generate diverse patterns through a much more complex evolution of forces than we could ever apply by hand (12), but ceding control over all but the starting materials leaves little opportunity to fine-tune structures or control stages of hierarchical development, let alone rationally design arbitrary architectures. Strategies inspired by biomineralization have been explored as potential routes to controlling growth and self-assembly from the molecular level via tailored microenvironments, epitaxy and inorganic or organic additives (13-24). Yet although these have produced some interesting spherical, spiral, leaf-like, and other shapes (25-32), it is rather disappointing that the appearance of various forms in synthetic systems is often unexpected and the attempts to identify the mechanisms of their formation are generally assessed a posteriori..

The vast majority of efforts to apply biomineralization principles to synthetic strategies have - like most nanoscale self-assembly techniques - focused primarily on defining the initial conditions or solution composition. While this approach has certainly yielded useful insights, many complex patterns emerge specifically in response to a dynamic environment: abrupt switches in marine shell patterning have been attributed to changes in conditions during growth (1); at a larger scale, bacteria form hierarchically structured 
communities by chemotactically responding to continuously changing chemical cues (33). This perspective not only highlights a major source of complexity and hierarchy currently missing from synthetic strategies, but also suggests we might be able to actively shape selfassembling structures by manipulating the environment as they grow. This possibility is especially compelling for systems that develop through reaction-diffusion processes, where dynamic feedback between the reaction front and the solution is the central mechanism of pattern evolution (34-40). Such feedback mechanisms are not only proposed to produce a variety of biological morphologies, but can also generate patterned precipitation in synthetic systems (41). We therefore explore whether mineralized forms can be precisely sculpted and hierarchically assembled into novel, arbitrary architectures through dynamic, rationally programmed modulations of the reaction solution.

In this work, we demonstrate how the responsive growth of structures toward or away from the bulk solution can be exploited to program a variety of "elementary" growth patterns, and derive sequences of simple, subtle modulations of $\mathrm{CO}_{2}, \mathrm{pH}$, and temperature that serve as building strategies for intricate, user-defined higher-order microstructures. Using continuous and/or stepwise adjustments, we steer the precipitating reactants via precise sculpting and sequential combinatorial assembly of the developing shapes.

\section{Hypothesis for structure evolution in a field of chemical gradients}

Our strategy for dynamically modulating structure evolution is based on the idea that the developing structure is continuously shaped by a complex spatial field of overlapping chemical gradients, created by the interplay between the bulk solution, the reaction front, and potentially neighboring structures. We analyze this growth process for the co-precipitation of $\mathrm{SiO}_{2}$ and $\mathrm{BaCO}_{3}$ in an alkaline aqueous solution containing $\mathrm{Na}_{2} \mathrm{SiO}_{3}$ and $\mathrm{BaCl}_{2}$, where precipitation is triggered by the diffusion of $\mathrm{CO}_{2} . \mathrm{BaCO}_{3}$ deposition increases with increasing $\mathrm{pH}$, while $\mathrm{SiO}_{2}$ deposition takes place in a narrow, optimum $\mathrm{pH}_{\mathrm{SiO} 2}$ range (42), and mutual feedback between the two processes may create a reaction-diffusion scenario. We hypothesize that the $\mathrm{pH}$-dependent feedback between $\mathrm{BaCO}_{3}$ and $\mathrm{SiO}_{2}$ deposition leads to distinct growth regimes, each with a distinct set of morphologies that can be evoked by small changes in the environment, as follows:

Regime 1: Starting with a high-pH bulk solution (region 1 in Fig. 1A), no silica deposition will take place and the influx of $\mathrm{CO}_{2}$ will trigger the precipitation of $\mathrm{BaCO}_{3}$ according to a simplified reaction: $\mathrm{Ba}^{2+}+\mathrm{CO}_{2}+\mathrm{H}_{2} \mathrm{O} \rightarrow \mathrm{BaCO}_{3}+2 \mathrm{H}^{+}$. The released $\mathrm{H}^{+}$will gradually lower the local $\mathrm{pH}$ at the growth front, until entering the $\mathrm{pH}$ range for silica precipitation according to a simplified reaction: $\mathrm{SiO}_{3}{ }^{2-}+2 \mathrm{H}^{+} \rightarrow \mathrm{SiO}_{2}+\mathrm{H}_{2} \mathrm{O}$, which then shifts the reaction equilibrium and solubility back toward $\mathrm{BaCO}_{3}$ precipitation, resulting in the continuous co-precipitation of $\mathrm{BaCO}_{3}$ and $\mathrm{SiO}_{2}$ (26). This scenario will have several consequences for the developing structure: a) crystal growth is passivated where silica precipitates, b) structures should grow most successfully toward the bulk solution where $\mathrm{pH}$ is above the range for silica deposition, and c) growth should be inhibited near the lowered $\mathrm{pH}$ of neighboring growth fronts. Depending on the nucleation density, different basic morphologies might be expected: half-spheres at low nucleation densities, or cones and stem shapes at higher densities, where neighboring diffusion fields steer the structures away from each other toward regions of higher $\mathrm{pH}$ (Fig. 1B). 


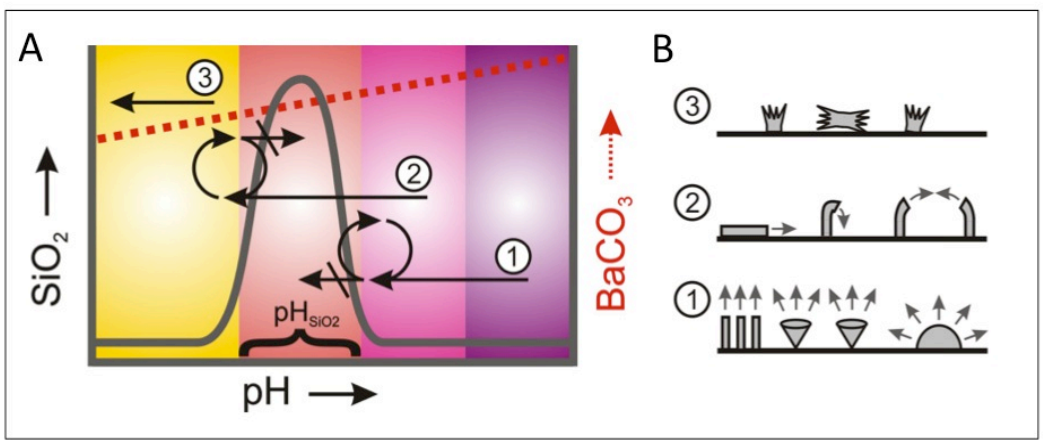

Fig 1. Schematic representation of the rate of $\mathrm{SiO}_{2}(26)$ (solid grey line) and $\mathrm{BaCO}_{3}$ precipitation (dashed red line) in the range of $\mathrm{pH}$ 8-12 (A) and anticipated shapes and growth directions (B) resulting from the three proposed growth regimes (see text for details). In all cases, growth will begin with the nucleation of $\mathrm{BaCO}_{3}$, which will lead to the local reduction of $\mathrm{pH}$ at the growth front. In Regime 1, the associated $\mathrm{pH}$ drop brings the structures to the right side of the silica deposition range (denoted as $\mathrm{pH}_{\mathrm{SiO} 2}$ ), giving rise to the continuous co-precipitation of $\mathrm{BaCO}_{3}$ and $\mathrm{SiO}_{2}$. The structures are expected to grow most successfully away from one another and towards the solution where $\mathrm{pH}>\mathrm{pH}_{\mathrm{SiO} 2}$, while other growth directions associated with lower $\mathrm{pH}$ become passivated by silica. Depending on the nucleation density, we expect the structures to "blossom" into stems, cones and half spherical shapes. In Regime 2, the $\mathrm{pH}$ drop from carbonate deposition will lower the $\mathrm{pH}$ at the growth front to $\mathrm{pH}<\mathrm{pH}_{\mathrm{SiO} 2}$, whereas the bulk solution remains more alkaline with $\mathrm{pH}<\mathrm{pH}_{\mathrm{SiO} 2}$. In this case, any growth directions toward the higher $\mathrm{pH}$ bulk solution will be blocked by the silica precipitation, and the structures are expected to grow most successfully away from the solution, along the interface or curl down and toward each other where $\mathrm{pH}<\mathrm{pH}_{\mathrm{SiO} 2}$ following the trail of produced acid. In Regime 3 , only $\mathrm{BaCO}_{3}$ crystals are expected to form.

Regime 2: Lowering the initial bulk $\mathrm{pH}$ can generate a scenario in which the local $\mathrm{pH}$ is below the optimum $\mathrm{pH}$ for silica formation $\left(\mathrm{pH}_{\mathrm{SiO} 2}\right)$ whereas the bulk $\mathrm{pH}$ is still above $\mathrm{pH}_{\mathrm{SiO} 2}$ (region 2 in Fig. 1A). In this case, the local decrease in $\mathrm{pH}$ due to continuing $\mathrm{BaCO}_{3}$ crystallization prevents, rather than promotes, the formation of $\mathrm{SiO}_{2}$ close to the growth front, whereas the influx of the bulk solution with $\mathrm{pH}>\mathrm{pH}_{\mathrm{SiO} 2}$ brings the solution into the $\mathrm{pH}_{\mathrm{SiO} 2}$ range and triggers the precipitation of $\mathrm{SiO}_{2}$ that passivates growth. Structures then grow most successfully away from the bulk solution, either along the interface to form flat sheets, or curling down and towards each other to preserve a low $\mathrm{pH}$ at the growth front (Fig. 1B).

Regime 3. If the $\mathrm{pH}$ of the bulk solution is below the $\mathrm{pH}_{\mathrm{SiO} 2}$ range, only "normal" $\mathrm{BaCO}_{3}$ structures should form (region 3, Fig. 1).

\section{Testing Regime 1: Solution-directed growth of stems, vases and corals}

As a first step toward testing the solution-dependent growth of structures in Regime 1, we created a gradient of $\mathrm{CO}_{2}$ concentrations by vertically positioning an aluminum plate or goldcoated glass substrate in a beaker containing an aqueous solution of $\mathrm{BaCl}_{2}(19.1 \mathrm{mM})$ and $\mathrm{Na}_{2} \mathrm{SiO}_{3}(8.2 \mathrm{mM})$ at a $\mathrm{pH}$ of 11.8 , and loosely covering the beaker to let $\mathrm{CO}_{2}$ from the air diffuse into the system (Fig. 2A). The nucleation density of $\mathrm{BaCO}_{3}$, gradually decreases with depth, in accord with the decrease in $\mathrm{CO}_{2}$ concentration. Within two hours, the nucleated $\mathrm{BaCO}_{3}$ bundles develop into a dense forest of thin stems at the top of the substrate, where the $\mathrm{CO}_{2}$ concentration is highest (Fig. 2A, Fig. S1). At intermediate depths the structures instead become vase-like, and form coral-like hemispherical shapes toward the bottom. In all cases, the structures grow perpendicular to the substrate - toward the bulk solution where $\mathrm{pH}>\mathrm{pH}_{\mathrm{SiO} 2}$ - and veer away from each other. The basic morphologies and behavior are thus consistent with the solution-directed growth mechanism proposed for Regime 1. Yet at the same time, the intricate wall structures observed in the vases and corals provide another level of complexity within each of the basic shapes, supporting the idea that this growth mechanism also contains the seeds for more complex modulations. 


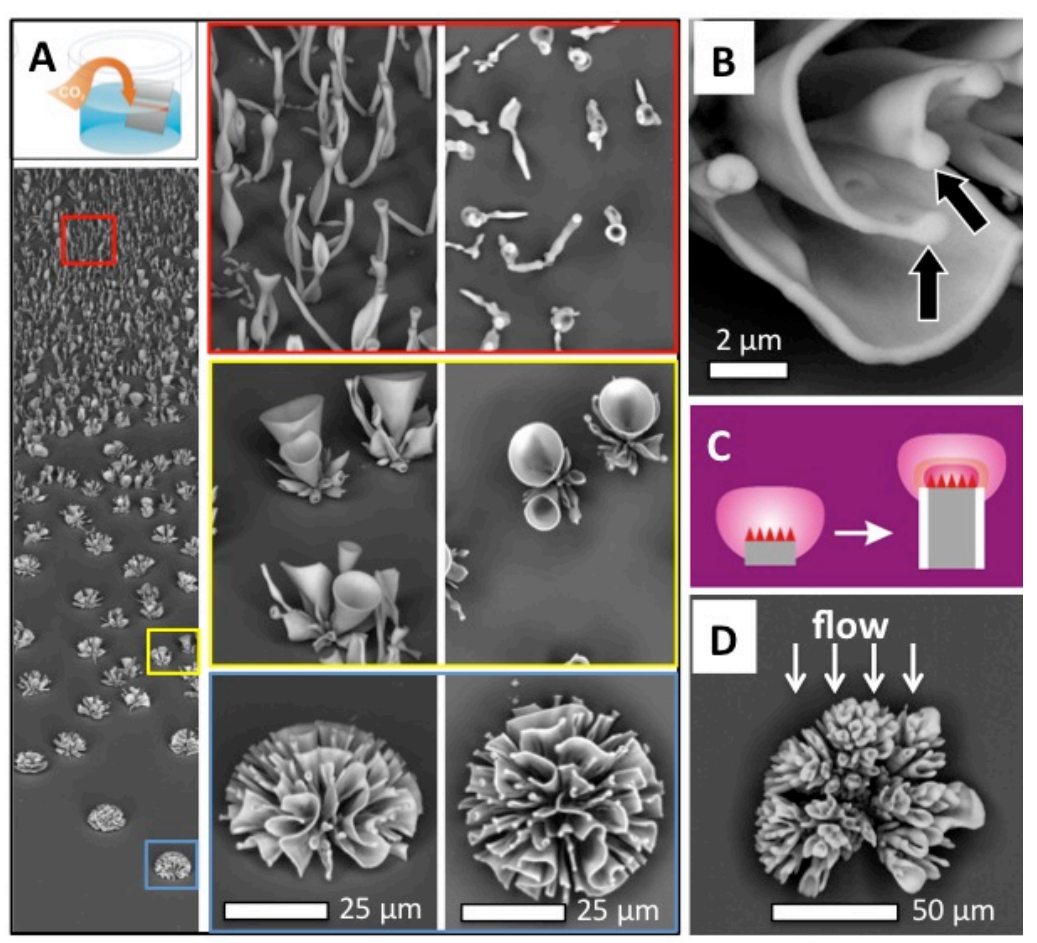

Fig. 2. Diversity of structures that grow in Regime 1. (A) SEM image of a typical substrate vertically submerged in solution with an initial bulk $\mathrm{pH}$ of 11.8 , showing a gradient of shapes (from top to bottom of the substrate: 1D stems, conical vases and half-spherical coral-like structures). The enlarged side and top views of the structures in the red, yellow and blue region are shown on the right. (B) High magnification SEM images of a coral structure, showing the thickening of the sides of the walls (indicated by arrows). (C) Schematic of a 2D growth mechanism, in which the thickness of the walls and stems is fixed by the short-range buffering action of silica deposited on the walls that locally increases $\mathrm{pH}$ at the $\mathrm{BaCO}_{3}$ growth front. (D) Top view of the coral structure grown in a flow in a microfluidic reactor. Directional growth towards the flow, where the $\mathrm{pH}$ is highest is observed, consistent with the predicted solution-directed growth behavior.

Indeed, close analysis of the wall structures reveals that these detailed features also form according to the same fundamental, solution-directed growth mechanism that forms the basic shapes. Inspection by scanning electron microscopy (SEM) reveals that the walls have a constant thickness of $\sim 1 \mu \mathrm{m}$, with a consistent thickening of stems and at the edges of the walls (Fig. 2B)..The constant wall thickness is consistent with a 2D growth mechanism, in which precipitation merely occurs at the active top edges of the structures while being inhibited by silica at the sides. Selective dissolution of $\mathrm{BaCO}_{3}$ using $\mathrm{HCl}(0.5 \mathrm{~mol} / \mathrm{L})$ leaves behind a hollow silica shell (Fig. S2), further indicating that the silica mainly deposits on and selectively passivates the sides of the walls where the $\mathrm{pH}$ is lowest (Fig. 2C). This localized silica precipitation sets the thickness of the walls, since the $\mathrm{pH}$ in the middle of the growth front is less buffered than closer to the sides where silica precipitation mainly occurs, allowing a new layer of $\mathrm{BaCO}_{3}$ crystals to grow at the top of the walls. The increased thickness at the edges of the walls and stems is also consistent with solution-directed growth: these areas have a larger surface to accommodate the silica deposition, resulting in local thickening (Fig. 2B). The localized feedback also produces a uniform 2D growth front by dampening the formation of spontaneous protuberances. To directly demonstrate that the structures evolve towards the highest $\mathrm{pH}$, we grew them in a continuous flow that increased the $\mathrm{pH}$ at the growth front using a microfluidic device. The structures primarily grow against the flow along the interface (Fig. 2D), in the direction of the high-pH bulk solution.

This basic, relatively simple directed growth behavior thus enables both straightforward selection and continuous sculpting of the evolving structures into a diversity of well-controlled forms. For example, the wall thickness can be dynamically modulated by increasing and decreasing the flux of $\mathrm{CO}_{2}$. A temporary increase in $\mathrm{CO}_{2}$ was imposed by opening the lid of the beaker, resulting in a thickening of the walls due to the increased carbonate deposition (Fig. 3A, S3). This thickening occurs only at the growth edge and the original wall/stem thickness is rapidly restored by the feedback mechanism when the lid is placed back on. As the growth rate is linear in time, we are able to use rhythmical fluctuations in the $\mathrm{CO}_{2}$ concentration to produce well-defined series of ripples (Fig. 3B). 

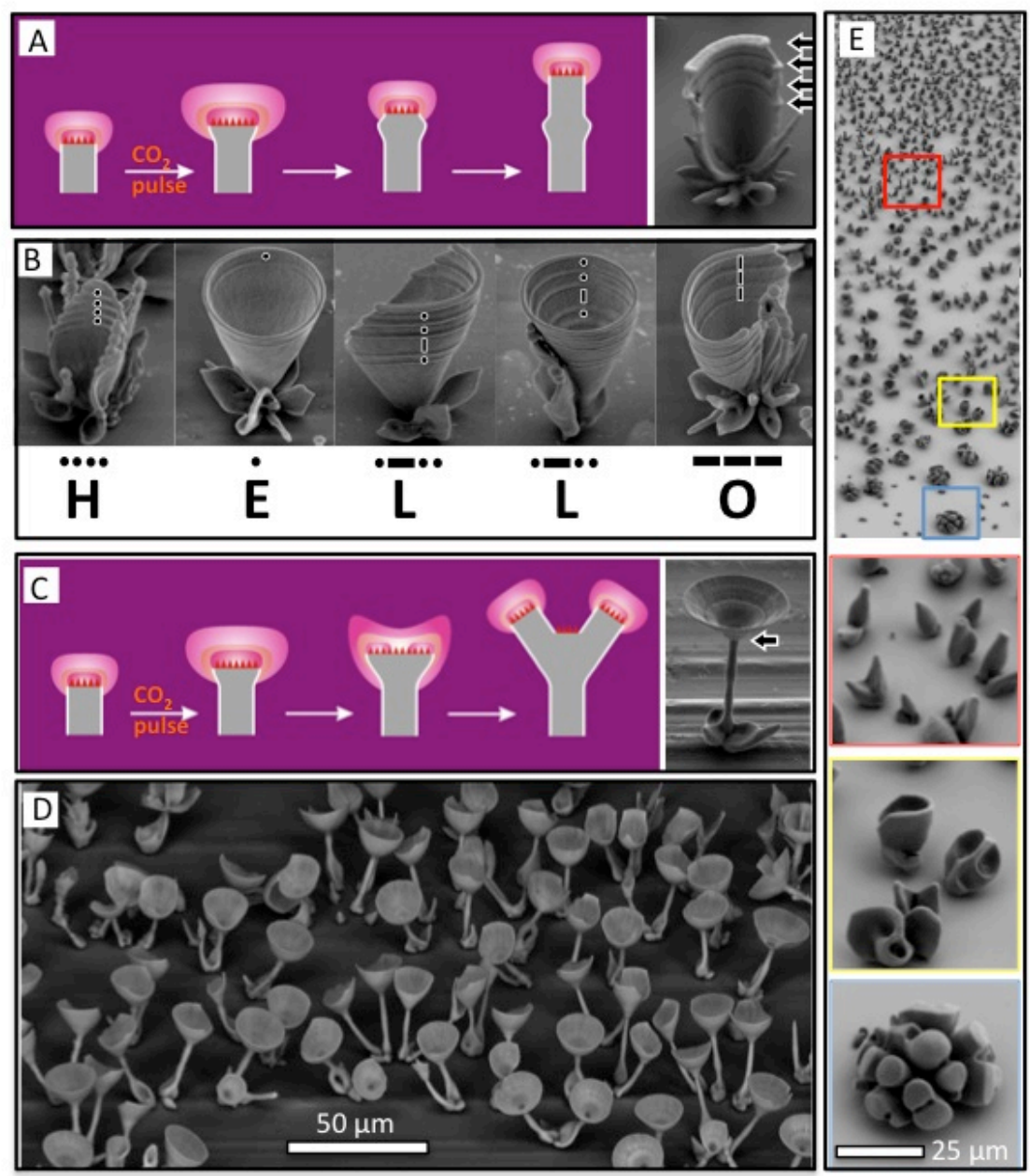

Fig. 3. Dynamically sculpting the growing stems, vases and corals. (A) Schematic of the mechanism of restoration of the original, well-defined wall thickness after a temporary increase of the wall thickness is induced (by for instance, a pulse of $\mathrm{CO}_{2}$ ). (B) Experimental demonstration of (A). Rhythmical pulsing of $\mathrm{CO}_{2}$ in the $\mathrm{Ba} / \mathrm{Si}$ solution controllably produces ripples in the growing structures that can be used to write messages in Morse code. The different letters are made in separate experiments; the "L" structures are from the same experiment. (C) Schematic of the proposed mechanism of the splitting of the growth front to restore the original dimension, when the temporary increase of the wall thickness exceeds the dimension of the buffering front established by silica on the side walls. (D) Experimental demonstration of splitting using a pulse of $\mathrm{CO}_{2}$ into a $\mathrm{Sr} / \mathrm{Si}$ solution, allowing to sculpt stems into vases. (E) The structures can also be thickened, while preserving the overall morphologies, by increasing either the availability of $\mathrm{CO}_{2}$ or the rate of the silica precipitation, which are achieved by lowering of the temperature (shown) or addition of $\mathrm{NaCl}$, respectively.

This control over wall thickness further provides the means to control how the growth front splits and branches. If the wall thickness exceeds a particular size, the center of the growth front is not sufficiently buffered by the silica deposition at the sides to continue growing, leading to a complete break-up of the growth front into new, separate growth fronts that branch away from each other (Fig. 3C). To reach such increased thicknesses, we performed experiments using $\mathrm{SrCO}_{3}$ in place of $\mathrm{BaCO}_{3} . \mathrm{SrCO}_{3}$ yields the same set of morphologies, but since its solubility is half that of $\mathrm{BaCO}_{3}$, a similar $\mathrm{CO}_{2}$ pulse results in the precipitation of more carbonate and induces a significantly greater thickening of the wall, inducing stems to open out into uniform vases (Fig. 3D). Perturbation of the thickness of the growth front by increased carbonate deposition can thus be swiftly restored to the original dimension either by slimming (Fig. 3A) or complete splitting of the front (Fig. 3C), depending on the precise magnitude of the perturbation, 
In addition to directly modulating $\mathrm{CO}_{2}$ or replacing $\mathrm{BaCO}_{3}$ with $\mathrm{SrCO}_{3}$, the structures can also be finely sculpted by modulating the temperature or salt concentration of the bulk solution. Lowering the temperature provides an alternative means to increase the amount of available $\mathrm{CO}_{2}$, and, indeed, we observe a thickening of the walls, while preserving the overall shapes of the stems, vases and corals, by simply cooling the solutions to $4^{\circ} \mathrm{C}$ (Fig. $3 \mathrm{E}$ ). Adding $\mathrm{NaCl}$ increases the silica deposition rate (41), which leaves the $\mathrm{BaCO}_{3}$ crystallization virtually unaffected (Fig. S4). Again, this leads to a thickening of the walls to give similar structures as shown in Fig. 3E. A variety of simple continuous modulations in the bulk solution can thus be used to dynamically steer the shape of the growing structures, allowing multiple levels of controlled sculpting.

\section{Testing Regime 2: Further diversity through inward-directed growth}

When we shift to Regime 2 by lowering the $\mathrm{pH}$ of the bulk solution to 11.2 , we observe an entirely different collection of shapes (Fig. 4A) (44). The basic shapes, including single- and double-spirals, globular and leaf-like structures, are consistent with the curling mode of growth and resemble those reported previously (28-30). In contrast to the pronounced gradient of structural variation observed in Regime 1, here even a single set of bulk conditions gives rise to a tremendous diversity of structures that not only grow next to each other but even appear together as part of composite structures. This diversity can be explained by considering how structures grow to avoid the passivating $\mathrm{pH}_{\mathrm{SiO} 2}$ range: while in Regime 1 the structures grow toward the bulk solution where $\mathrm{pH}>\mathrm{pH}_{\mathrm{SiO} 2}$ and away from neighbors, in Regime 2 their growth appears inward, away from the bulk solution and toward their own and neighboring growth fronts where $\mathrm{pH}<\mathrm{pH}_{\mathrm{SiO} 2}$. Indeed, in direct support of this mechanism, structures growing in a microfluidic reactor at $\mathrm{pH} 11.2$ point away from the bulk solution (Fig. 4B) developing in the direction opposite of that observed in Regime 1 (see Fig. 2D). This inward-directed growth can be expected to make the emerging shapes highly sensitive to small variations in local diffusion fields, driving a more intricate chemical interplay between nearby structures and different regions of their own surfaces.

The simultaneously appearing basic shapes can each be understood by the inward directed growth that characterizes Regime 2 (Fig. 4C-F; see Fig. S6 for details): 1) Large leaf-like structures covered with a mantle of silica (Fig. 4C) arise when the nucleated $\mathrm{BaCO}_{3}$ crystals grow along the substrate, where the $\mathrm{pH}$ in the vicinity of the growth front remains sufficiently low $\left(\mathrm{pH}<\mathrm{pH}_{\mathrm{SiO} 2}\right)$ to prevent passivation by silica precipitation, whereas silica deposition occurs on top of the structure due to the flux of a more basic solution from the bulk. 2) Single spirals form in response to perturbation of the growth front of the nucleated $\mathrm{BaCO}_{3}$ crystals that results in a lower $\mathrm{pH}$ at one side of the front and a higher $\mathrm{pH}$ at the opposite side. The lowering of the local $\mathrm{pH}$ causes two complementary effects - growth towards the lower $\mathrm{pH}$ to remain in the region of $\mathrm{pH}<\mathrm{pH}_{\mathrm{SiO} 2}$ and, conceivably, a slightly decreased $\mathrm{BaCO}_{3}$ growth rate of the inner side of the curved structure. As the outer part continues growing and is passivated by silica, this further shields the inner part from the bulk solution, lowering the local $\mathrm{pH}$ inside even more. The structure will continue to curl in this direction to give an increased curvature, until the front is hampered by its own tail (Fig. 4D). 

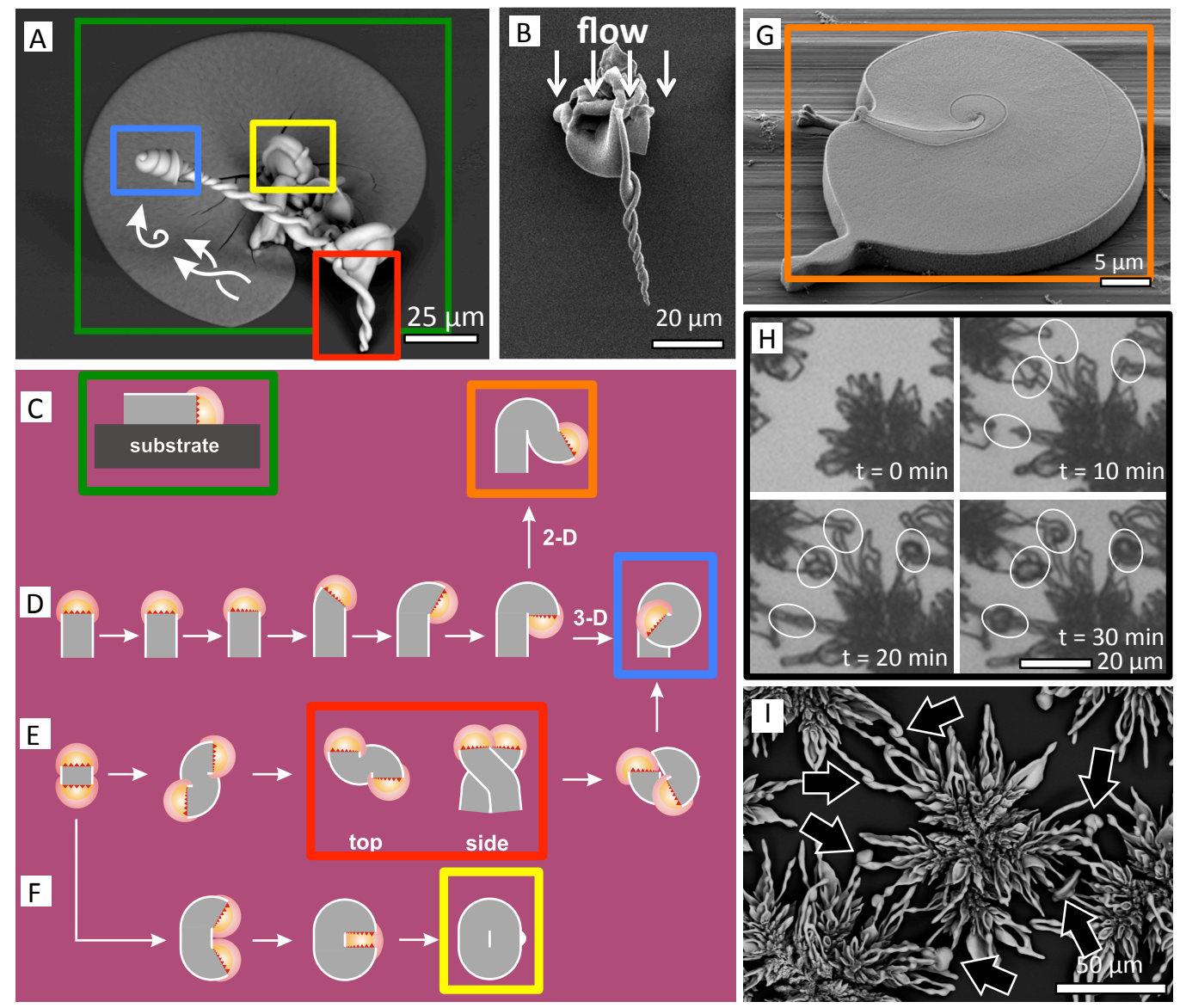

Figure 4. Diversity of structures that grow by inward-directed growth in Regime 2. (A) SEM image of an exemplary $\mathrm{BaCO}_{3} / \mathrm{SiO}_{2}$ structure grown at $\mathrm{pH} 11.2$ containing single spiral (blue rectangle), double spiral (red rectangle), leaf shapes (green rectangle) and globular shapes (yellow rectangle). (B) Top view of a spiral grown in a flow., demonstrating directional growth away from the flow of bulk solution. (C) Leaf-like structures grow along the interface, away from the solution and become passivated on the top by a silica mantle. (D-F) Mechanisms of three curling modes, in which the structures curve away from the bulk solution and follow the trail of the acid produced at their own or neighboring growth front, resulting in the formation of single (D) and double (E) spirals and globular (F) structures (see text and SI for details). (G) Demonstration of the curling mode in a thin film of the solution that only allows to meander in $2 \mathrm{D}$ and eventually ceases when crashing into their own tail. (H) Optical microscopy time lapse series of a dense field of structures that initially $(\mathrm{t}=0 \mathrm{~min})$ were grown in Regime 1 and then merge together upon lowering of the $\mathrm{pH}$ to create spirals, indicated by arrows in (I).

To visualize this initial curling, we developed a method to grow quasi-2D structures by pinning the meniscus on the substrate (Fig. 4G). If we allow the structures to grow in 3D, the growth front continues to curl in the same direction, thereby following the acid that is produced by the previously formed part of the structure and generating a single spiral. This underlying part also shields the growth front from the bulk solution, comparable to the manner in which the substrate promotes the growth of the leaves. 3) Double spirals emerge when, instead of following its own tail, a growth front bends in the direction of the acid produced by a nearby $\mathrm{BaCO}_{3}$ growth front. In this case the two active sites follow each other's tails, making a double spiral (Fig. 4E). To confirm this cooperative growth mechanism, we grew a dense field of structures in Regime 1 and subsequently lowered the $\mathrm{pH}$ to the curling growth mode. As can be observed from Fig. 4H-I, the structures, which first grow away from each other and into the solution in Regime 1, begin to "sense" each other's active growth fronts, grow towards each other and away from the bulk, and finally merge to form single and double spirals in Regime 2, in agreement with the hypothesis presented in 
Fig. 1. When one of the growth fronts of the double spiral catches up with the other one, they combine to form a single spiral with preservation of the chirality (Fig. 4A,E). 4) Finally, globular structures can be formed when two growth fronts crash into each other and merge together to become completely passivated by silica (Fig. 4F). The abundant acid that is released produces a local thickened scar on the silica mantle that is found on most globular structures (Fig. 4A).

The formation of spirals, double spirals, leaves and globular shapes can thus be explained by growth-induced localized acid formation that lowers the $\mathrm{pH}$ below the optimum for silica precipitation that passivates the growth, inducing structures to (i) grow most successfully away from the bulk solution and towards each other, (ii) curl as a result of the non-uniform growth rates that arise from the $\mathrm{pH}$-dependent solubility (45).

\section{Beyond basic shapes: Hierarchical combinatorial architectures}

Since the morphology of the growing structures is responsive to the solution conditions and independent of the underlying form, a wide variety of different shapes can be stacked on top of each other by controlling the position, $\mathrm{pH}$, temperature and salt concentration in serial growth steps (Fig. 5, S7-9). When structures are grown sequentially in two different growth solutions, the second precipitation takes place preferentially at the active barium or strontium carbonate growth sites of the already existing structures, showing no overgrowth of silica-passivated surfaces. We illustrate this by comparing the same structures before and after the second growth using SEM and confocal microscopy of dyed solutions (Fig. 5A,B). For instance, if we first grow spirals containing the green dye fluorescein in Regime 2 and then increase $\mathrm{pH}$ to grow coral-like structures in the presence of the red dye rhodamine B in a subsequent step, we program complex hierarchical structures (Fig. 5A-C). By simply positioning the substrate at an angle relative to the first growth, we create a combinatorial matrix of reaction conditions that yield a large structural diversity with regions exhibiting well-defined hierarchical shapes on a single sample (Fig. 5D). 

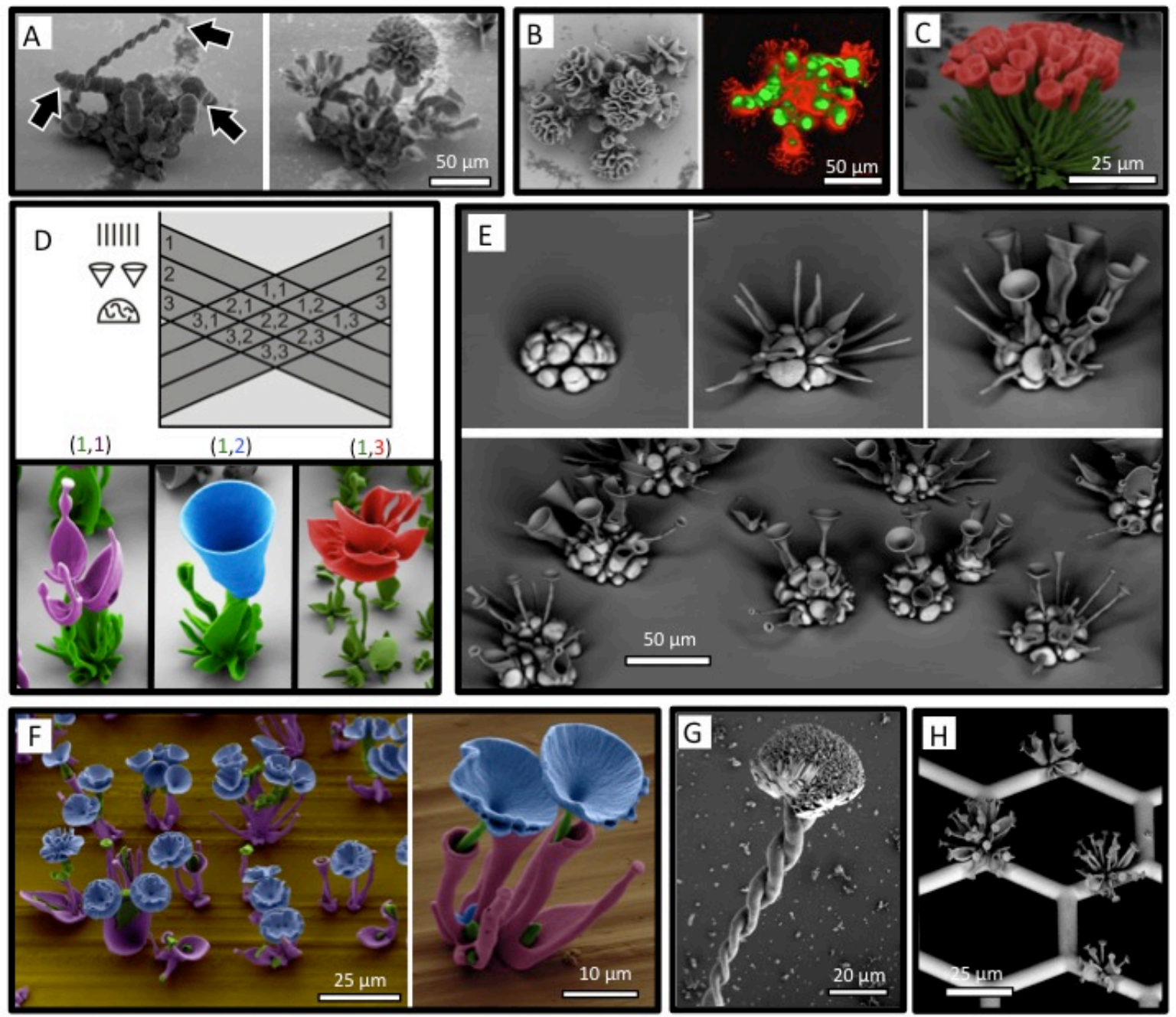

Fig. 5. Controlled synthesis of exemplary hierarchical complex structures. (A-B) Hierarchical $\mathrm{BaCO}_{3} / \mathrm{SiO}_{2}$ structures grown first in the solution containing fluorescein at $\mathrm{pH} 11.2$ (Regime 2) and then transferred to a new solution containing rhodamine B at pH 11.8 (Regime 1). Subsequent SEM images of the same structure (A) and confocal microscopy images (B) show that coral-like formations grow selectively on the active sides of the spirals (indicated by arrows in A) and no overgrowth occurs at the side walls of the previously-formed shapes. (C) The SEM is false-colored, but represents the actual color of the structure composed of green $\mathrm{SrCO}_{3} / \mathrm{SiO}_{2}$ stems grown at $\mathrm{pH} 11.8$ in the presence of fluorescein and then decorated with red, thick-walled $\mathrm{BaCO}_{3} / \mathrm{SiO}_{2}$ vases grown at $4^{\circ} \mathrm{C}$ in the presence of rhodamine $\mathrm{B}$ at $\mathrm{pH}$ 11.8. (D) Approach for making a combinatorial matrix of morphologies by changing the orientation of the substrate in distinct growth steps to stack different morphologies on top of each other. The SEMs of representative structures are false-colored to mark parts of the structure grown in different steps. (E) Multi-material structure made in three steps: first, growing $\mathrm{BaCO}_{3}$ corals that were thickened by addition of $\mathrm{NaCl}$ (top-left), and, subsequently, inserting $\mathrm{SrCO}_{3}$ stems (top-center) and opening with a pulse of $\mathrm{CO}_{2}$ (top-right). The series is compiled from different structures. Bottom: a large-area view. (F) False-colored $\mathrm{SEMs}$ showing a field of purple $\mathrm{Sr} / \mathrm{Si}$ vases containing $\mathrm{Sr} / \mathrm{Si}$ stems (green) that subsequently were opened with a $\mathrm{CO}_{2}$ pulse (blue). (G) A spiral grown in Regime 2 evolves into naked $\mathrm{BaCO}_{3}$ crystals of Regime 3 by lowering of the $\mathrm{pH}$ of the bulk solution. (H) TEM grid decorated with $\mathrm{SrCO}_{3} / \mathrm{SiO}_{2}$ stems that are opened with a $\mathrm{CO}_{2}$ pulse. A larger variety of structures and overview images are provided in the supporting information (Fig. S7-9).

When the structures grown in the first step become overcoated with $\mathrm{SiO}_{2}$, these sites become passivated, so that the only nucleation sites available for the second precipitation are hidden in the cavities of the structure where growth fronts split (Fig. 3C). For instance, $\mathrm{BaCO}_{3}$ structures that form either in the presence of $0.2 \mathrm{mM} \mathrm{NaCl}$ or at low temperature (SI) give corals with thickened passivated walls that subsequently can be ingrown with $\mathrm{SrCO}_{3}$ stems that are then opened with a $\mathrm{CO}_{2}$ pulse (Fig. 5E). Similarly, the active growth sites in 
the cavities of the vases were used to nucleate stems that were then opened with a pulse of $\mathrm{CO}_{2}$ (Fig. 5F). When the $\mathrm{pH}$ of the solution is reduced during the experiment from Regime 2 to Regime 3, spiral formations become overgrown by pure $\mathrm{BaCO}_{3}$ bundles (Fig. 5G). Additionally, patterned substrates can be selectively decorated with structures (Fig. $5 \mathrm{H}$ ). In all cases, the sculpted complex architectures show an unprecedented level of structural uniformity over large areas (see representative examples in Fig. 3D, 5E,F and S7-9).

The separate growth steps thus make it possible to create combinatorial, hybrid structures in which a judicious choice of the conditions is used to stack multiple shapes and sculpt continuously during the growth.

\section{Conclusions}

Sequential modulations of environmental conditions such as $\mathrm{pH}$, temperature, and $\mathrm{CO}_{2}$ concentration are used to modify local chemical fields that directly influence the growth front and control directional structure evolution. We identify two distinct and complementary growth modes: 1) a "blossoming" regime, in which the structures grow away from each other and toward the bulk solution to form stems, vases and corals; and 2) a "curling" regime, in which the growing fronts tend to shield themselves from the bulk solution by curling back toward themselves and each other to form spiral and leaf structures. Detailed understanding of the underlying buffering mechanisms allows us not only to program these elementary shapes, but to dynamically sculpt and pattern evolving structures and precisely assemble them inside or on top of each other to generate hierarchically assembled multiscale architectures with unprecedented levels of complexity and precision.

\section{References and Notes}

1. P. Ball, The self-made tapestry (Oxford University Press, UK 1999)

2. D. W. Thompson, On Growth and Form (Cambridge Univ. Press, UK 1942).

3. P. Vukusic, J. R. Sambles, Nature 424, 852 (2003).

4. K.-H. Chu, R. Xiao, E. N. Wang, Nature Mat. 9, 413 (2010).

5. J. Aizenberg, et al., Science 309, 275 (2005).

6. J. K. Gansel et al., Science 325, 1513 (2009).

7. J. Ge, J. Lei, R. N. Zare, Nature Nanotech. 7, 428 (2012).

8. K. H. Sandhage et al., Nature 446, 172 (2007).

9. B. Lim et al., Science 324, 1302 (2009).

10. S. Kawata, H.-B. Sun, T. Tanaka, K. Takada, Nature 412, 697-698 (2001).

11. M. J. Madou, Fundamentals of Microfabrication: The Science of Miniaturization (CRC Press; US, 2002).

12. G. M. Whitesides, B. Grzybowski, Science 295, 2418 (2002).

13. H. A. Lowenstam, S. Weiner, On biomineralization (Oxford University Press, UK 1989).

14. P. Harting, Quarterly J. Microscopy Soc 12, 118 (1872).

15. S. Oliver, G. A. Ozin, L. A. Ozin Adv. Mat. 7, 948 (1995).

16. J. J. Pagano, T. Bánsági, Jr., O. Steinbeck, Angew. Chem. Int. Ed. 47, 9900 (2008). 
17. J. H. E. Cartwright, J. M. García-Ruiz, M. L. Novella, F. Otálora, J. Colloid Interface Sci. 256, 351 (2002).

18. C. Ritchie et al., Nature Chem. 1, 47 (2009).

19. S. Mann, Nature 365, 499 (1993).

20. S. Mann, Angew. Chem. Int. Ed. 39, 3392 (2000).

21. S. Mann, G. A. Ozin Nature 382, 313 (1996).

22. G. Falini, S. Albeck, S. Weiner, L. Addadi, Science 271, 67 (1996).

23. S. V. Patwardhan, S. J. Clarson, C. C. Perry, Chem. Commun. 1113-1121 (2005).

24. H. Y. Li, H. L. Xin,, D. A. Muller, L. A. Estroff, Science 326, 1244 (2009).

25. S.-H. Yu, H. Colfen, K. Tauer, M. Antonietti, Nature Mat. 4, 51 (2005)

26. L. A. Gower, D. A. Tirrell, J. Cryst. Growth 191, 153 (1998).

27. S. D. Sims, J. M. Didymus, S. Mann, J. Chem. Soc., Chem.

Comm. 10, 1031 (1995).

28. J. M. Garcia-Ruiz, E. Molero-Garcia, S. T. Hyde, Science 323, 362 (2009).

29. J. M. Garcia-Ruiz, J. L. Amoros, J. Cryst. Growth 55, 379 (1981).

30. J. M. Garcia-Ruiz et al., Science 302, 1194 (2003).

31. M. Kellermeier et al., Chem. Eur. J. 18, 2272 (2012).

32. T. Tarada, S. Yamabi, H. Imai J. Cryst. Growth 253, 435 (2003).

33. H. C. Berg, E. coli in Motion (Springer-Verlag, New York, US, 2003).

34. A. M. Turing, Philos. Trans. R. Soc. London. Ser. B 237, 37 (1952).

35. A. N. Zaikin, A. M. Zhabotinsky, Nature 225, 535 (1970).

36. T. Bánsági Jr., V. K. Vanag, I. R. Epstein, Science 331, 1309 (2011).

37. I. Lengyel, I. R. I. Epstein, Science 251, 650 (1991).

38. G. Ertl, Science 254, 1750 (1991).

39. S. Kondo, T. Miura Science 329, 1616 (2010).

40. G. M. Whitesides, R. F. Ismagilov, Science 284, 89 (1999).

41. B. A. Grzybowski, Chemistry in Motion (John Wiley \& Sons Ltd., UK, 2009)

42. C. J. Brinker, G. W. Scherer, Sol-Gel science (Academic press inc. London, UK 1990)

43. W. L. Marshall, J. M. Warakomski, Geochim. Cosmochim. Acta 44, 915 (1980).

44. Our a priori model suggests that the bulk solution in regime 2 is above the optimum $\mathrm{pH}$ for silica formation, whereas in the vicinity of the growth front, the localized acid formation lowers the $\mathrm{pH}$ below the optimum $\mathrm{pH}$ to precipitate silica on the active growth sites. We confirmed this localized $\mathrm{pH}$ gradient by monitoring the $\mathrm{BaCO}_{3} / \mathrm{SiO}_{2}$ co-precipitation while deliberately adjusting the bulk $\mathrm{pH}$ (see supporting information).

45. We assume that the rate of the silica formation is slow enough to enter Regime 2 before a layer of silica is formed that locks the co-precipitation in Regime 1 . We verified this by starting from Region 2 and increasing the rate of silica precipitation rate by adding $0.2 \mathrm{mmol}$ 
$\mathrm{NaCl}$. As expected, we observe that the silica nucleation is now fast enough to not enter Regime 2 but indeed grow thickened blossoming structures that correspond to Regime 1.

\section{Acknowledgements}

We thank Dr. James C. Weaver for advice with the SEM imaging, Dr. Sindy K. Y. Tang and Roel Sadza for the microfluidic experiments and Laura Hendriks for growing the structures in Fig. 5F. WLN acknowledges the Netherlands Organization for Scientific Research for financial support. Electron microscopy was performed at Harvard's Center for Nanoscale Systems. 